\title{
Differentiation-Associated Expression of Conventional Protein Kinase C Isoforms in Primary Cultures of Bone Marrow Cells Induced by M-CSF and G-CSF
}

\author{
Xiaohua Li*, Hong Meng, Ben D. Chen \\ Barbara Ann Karmanos Cancer Institute, and Department of Internal Medicine, Wayne State University School of \\ Medicine, Detroit, Michigan 48201 \\ *Corresponding Author: \\ Xiaohua Li, Ph.D. \\ 9207 Scott Hall, 540 E. Canfield, Detroit, MI 48201 \\ Tel.: 313-993-4188 \\ Fax: 313-577-0057 \\ E-mail address: xhli@med.wayne.edu
}

Received: 15 November 2008; | Revised: 30 November 2008; | Accepted: 1 December 2008

\begin{abstract}
The Protein kinase C (PKC) -associated signal pathway plays crucial roles in regulation of cell growth, differentiation and apoptosis. The present study focuses on conventional PKC (cPKC) expression and its regulation in primary cultures of bone marrow cells induced to undergo macrophage/granulocyte differentiation by macrophage colony-stimulating factor (M-CSF) or granular colony-stimulating factor (G$\mathrm{CSF}$ ). By performing western blot analysis with pan anti-PKC antibodies, we found that PKC is transiently induced by M-CSF, reaching a maximum level by day 2, and then declines and diminishes by day 9 in primary culture of bone marrow cells. In contrast, the expression of PKC along G-CSF induced granulocytic differentiation of bone marrow stem cells is low and increases gradually. Reverse transcription-PCR (RTPCR) assay was utilized to investigate the expression of PKC isoforms. PKC- $\alpha$ is constitutively expressed in bone marrow cells independently of hematopoietic growth factors in cultures. PKC- $\gamma$ mRNA is undetectable. Similarly, the expression of PKC- $\beta$ is transiently induced by M-CSF, yet steadily increased by G-CSF, in agreement with results obtained from PKC protein expression. Furthermore, gel-shift assay showed that the activation of NF- $\kappa \mathrm{B}$ is transiently induced by M-CSF but not by G-CSF. These data suggest that PKC expression is involved in both macrophage and granulocyte differentiation by bone marrow committed stem cells. Yet, NF- $\kappa \mathrm{B}$ activation is only detected in macrophage and not granulocyte differentiation. Thus, we conclude that the PKC-mediated signaling pathway is distinctly involved in bone-marrow cell differentiation induced by M-CSF and G-CSF.
\end{abstract}

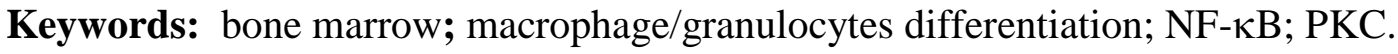




\section{Introduction}

Mature macrophages and granulocytes are derived from the same bone marrow-derived progenitor cells, known as colony-forming units for both granulocytes and macrophages (CFUGM). The production of mature macrophages and granulocytes is regulated by a group of hematopoietic growth factors referred to as colony-stimulating factors (CSFs). Among them, macrophage colony-stimulating factor (M-CSF) stimulates the differentiation and production of macrophages. Granulocyte colony-stimulating factor (G-CSF) stimulates predominantly the differentiation and production of granulocytes by bone marrow CFU-GM. M-CSF stimulates myeloid stem cells through a specific receptor encoded by the proto-oncongene $\mathrm{c}$-fms, a tyrosine kinase receptor, which transduces the differentiation signal for hematopoietic progenitor cells to develop along macrophage lineage [1-5]. When bone marrow cells are cultured with G-CSF, myeloid stem cells differentiate into the granulocytic lineage through the activation of the G-CSF receptor (also known as CD114). The GCSF-R has no intrinsic kinase activity but recruits cytoplasmic tyrosine kinases of both the Janus kinase (Jak) and Lyn kinase families, which activates signal transducer and activator of transcription (STAT) proteins $[3,6]$.

Members of the protein kinase $\mathrm{C}$ (PKC) family play a key regulatory role in a variety of cellular functions including cell growth and differentiation, and gene expression [7-9]. PKCs were originally identified as serine/threonine protein kinases whose activity was dependent on calcium and phospholipids. At least 12 isoforms of PKC have been identified, which are divided into three subgroups: conventional, novel and atypical PKC $[10,11]$. The expression of an individual $\mathrm{PKC}$ isoform is both cell and tissue type-specific [12-15]. Conventional PKCs (cPKCs) are calciumdependent $\mathrm{PKC}$ isoforms, of which there are three: PKC $-\alpha$, PKC $-\beta$ (including $\beta \mathrm{I}$ and $\beta \mathrm{II}$ ) and PKC- $\gamma$ $[16,17]$. The signaling pathways of PKCs are mediated through cell surface receptors, which transduce extra cellular signals into cells [18]. PKC- $\alpha$-mediated signaling serves as a cell survival factor $[19,20]$. PKC $-\beta$ is found to be associated with cell proliferation and differentiation $[15,21]$; PKC- $\beta$ ( $\beta \mathrm{I} / \beta \mathrm{II})$ mRNA increases in mouse brain and spleen after birth, while its expression in thymus decreases with age. Human lymphoid cell lines express large amounts of PKC- $\beta$ mRNA in addition to PKC- $\alpha$ mRNA. Most information about PKC- $\gamma$ is derived from studies on the nervous system; and its enzymatic activity is exclusively expressed in the central nervous system (brain and spinal cord). Thus PKC- $\gamma$ is believed to be important in the neural plasticity within the spinal cord after nerve injury, which contributes to neuropathic pain [22].

PKC is also known as a receptor for certain tumor promoter phorbol esters and plays a crucial role in the events related to tumor progression [18, $23,24]$. The differentiation obstacle of the cell is the major character of tumor occurrence. The expression and activation of certain PKC isoforms are known to be associated with tumor cell proliferation and/or differentiation, but the mechanism is still indistinct.

In this study, we examined the role of cPKC expression during mouse macrophage and granulocyte differentiation by bone marrow hematopoietic committed stem cells induced by M-CSF and G-CSF in cultures. We asked whether cPKC isoforms are differentially expressed when hematopoietic stem cells are induced to undergo differentiation along different lineages. In addition, we investigate the role of NF- $\kappa B$ activation in the process. We now report that the expression of PKC- $\beta$ isoforms is differentially regulated during macrophage and granulocyte differentiation. Furthermore, activation of NF- $\mathrm{KB}$ is detected only in cells undergoing macrophage differentiation.

\section{Materials and Methods}

\section{Reagents}

Recombinant human M-CSF was generously provided by Cetus Corp., (Emeryvill, CA). Recombinant human G-CSF was obtained from PeproTech (Rocky Hill, NJ). Fetal bovine serum (FBS) was purchased from HyClone Inc. (Logan, UT). Anti-protein kinase $\mathrm{C} \mathrm{mAb}$ (clone MC5, 
recognizing $\alpha, \beta$ and $\gamma$ isoforms) and anti-calpain 1 (clone N-19) were obtained from Santa Cruz Biotechbology, Inc. (Santa Cruz, CA). Rabbit anti$20 \mathrm{~S}$ proteasome ( $\alpha$-subunit) was purchased from CALBIOCHEM (San Diego, CA). M-MLV reverse transcriptase and random primers were purchased from Invitrogen (Carlshad, CA). Taq DNA Polymerase was purchased from Promega (Madison, WI).

\section{Primary culture of Bone Marrow Cells}

Female DBA/2J, Babl/c mice with 6 to 8 weeks of age were obtained from Jackson Laboratories (Bar Harbor, ME). Mouse bone marrow cells were collected from femoral shafts by flushing with $3 \mathrm{ml}$ of cold RPMI-1640 medium containing $15 \%$ FBS. Single cells suspension was obtained by passing through an 18 -g needle six times in RPMI-1640 to disperse cell clumps. Bone marrow adherent (AD) cells were removed by incubating at $37^{\circ} \mathrm{C}$ for $4 \mathrm{hr}$ in $\mathrm{T}-75$ Falcon culture flasks. To induce macrophage differentiation, the non-adherent (NA) bone marrow cells were cultured in RPMI-1640 medium containing $15 \%$ FBS and $10 \mathrm{ng} / \mathrm{ml}$ of M-CSF. To induce granulocytic differentiation, bone marrow NA cells were cultured in RPMI 1640 medium containing $15 \%$ FBS and $5 \mathrm{ng} / \mathrm{ml}$ of G-CSF. Human bone marrow cells were donated by healthy individual and obtained from bone marrow banks of the Detroit Medical Center.

\section{Western Blot}

Total cell lysates were boiled in an SDS gelloading buffer with DTT for $3 \mathrm{~min}$ and were subjected to electrophoresis on $10 \%$ onedimensional SDS-polyacrylamide gel. Proteins were transferred to a $0.2 \mu \mathrm{m}$ nitrocellulose membrane (Schleicher \& Shuell, Keene, NH) at $4^{\circ} \mathrm{C}, 14$ volts overnight. Nonspecific binding sites on the nitrocellulose membrane were blocked by incubating the membrane in blocking buffer $(5 \%$ nonfat milk in TBS-tween 20) for 1 hour at room temperature. The blots were washed by TBStween once and incubated for 2 hours at room temperature with the primary antibody. After the removal of extra primary antibody with three washes, the blots were incubated with a secondary antibody (goat anti-mouse or goat anti-rabbit antibodies conjugated with horseradish peroxidase) for 1 hour at room temperature. The membrane was developed with the enhanced chemiluminescence (ECL) reagent and exposed to Hyperfilm-ECL (Amersham Life Science Corp.) for visualization.

\section{Detection of conventional PKCs mRNA by RT- PCR}

Total RNA was extracted from bone marrow cells cultured with M-CSF or G-CSF, or from RAW 264.7 mouse monocyte-macrophage cell line, respectively, by using Trizol reagent according to the manufacture recommended procedure (Invitrogene, Carlsbad, CA). The RNA pellet was resolved in water and stored in $-70^{\circ} \mathrm{C}$ for reverse transcription reaction.

RNA was denatured with random primer and dNTP in water (total $12 \mu \mathrm{l}$ ) at $65^{\circ} \mathrm{C}$ for $6 \mathrm{~min}$ and quick chill on $4^{\circ} \mathrm{C}$. Single stranded cDNA was synthesized by add $5 \mathrm{x}$ first-strand buffer and DTT and M-MLV at $25^{\circ} \mathrm{C}$ for $10 \mathrm{~min}$ and $37^{\circ} \mathrm{C}$ for 50 min. The reverse transcription (RT) reaction was inactivated by heating at $70^{\circ} \mathrm{C}$ for $15 \mathrm{~min}$, followed by $4^{\circ} \mathrm{C}$ for $5 \mathrm{~min}$. Polymerase chain reaction (PCR) was conducted in reaction buffer (total volume $50 \mu \mathrm{l}$ ) consisted of $1.5 \mathrm{mM} \mathrm{MgCl}_{2}$, $200 \mu \mathrm{d}$ dNTP, 50 pmol each primers, 0.25U Taq DNA Polymerase, 5\% DMSO, $10 \mu \mathrm{l}$ solution of 1:10 diluted cDNA reverse transcriptase reaction product. After initial denaturation at $95^{\circ} \mathrm{C}$ for 4 min, amplification was performed for 45 seconds at $95^{\circ} \mathrm{C}, 1 \mathrm{~min}$ at $52^{\circ} \mathrm{C}$ and $1 \mathrm{~min}$ at $72^{\circ} \mathrm{C}$ for $30 \sim 35$ cycles using DNA thermal Cycler 480 (Perkin Elmer), followed by $72^{\circ} \mathrm{C}$ for $8 \mathrm{~min}$ and $4^{\circ} \mathrm{C}$ at least $4 \mathrm{~min}$. Mouse $18 \mathrm{~S}$ product was used as an internal control. The PCR products were identified and visualized by running through $1.5 \%$ agarose gel with ethidium bromide staining. The primers used for PCR were as follows [25, 26]: PKC- $\alpha$, forward: 5'-CGA GGA AGG AAA CAT GGA AC T CAG-3', reverse: 5'-TTT CCA CTA CGA ACG GCT GTC C-3'; PKC- $\beta$, forward: 5'-GAA CCG TC G ACC ATG GCT GAC CCG GCT GCG GGG-3', reverse: 5'-CTG GTC AGG TCC CAA TCC CCA3'; PKC- $\gamma$, forward: 5'-GAA CCG TCG ACC ATG GCG GGT CTG GGC CCT-3', reverse: 5'-ATC CC A ATC CCA CAC CTC CA-3'. 


\section{Electrophoretic mobility-shift assay (EMSA)}

The extraction of nuclear DNA binding proteins and NF- $\kappa \mathrm{B}$ DNA-binding activities was analyzed by electrophoresis mobility-shift assay (EMSA) [5]. Five $\mu \mathrm{g}$ of total protein of nuclear extract was incubated with ${ }^{32} \mathrm{P}$-labeled $\mathrm{NF}-\kappa \mathrm{B}$ oligonucleotides, 5'-GCC ATG GGG GGA TCC CCG AAG TCC-3' (Geneka Biotechnology Inc.) for $25 \mathrm{~min}$ at room temperature in a reaction buffer (10 mM Tris, $\mathrm{pH} 7.5,50 \mathrm{mM} \mathrm{NaCl}, 1 \mathrm{mM}$ DTT, $1 \mathrm{mM}$ EDTA. 5\% glycerol). The DNAprotein complexes were separated from free oligonucleotides on $4 \%$ native polyacrylamide gel containing $50 \mathrm{mM}$ Tris $\mathrm{pH} 7.5,0.38 \mathrm{M}$ glycine and $2 \mathrm{mM}$ EDTA. The gel was dried and examined by autoradiography.

\section{Results}

Protein kinase $\mathrm{C}$ expression in bone marrowderived macrophages and granulocytes

In the presence of M-CSF, the non-adherent bone marrow cells rapidly became differentiated toward macrophage lineage with adherent capability within 24 hours. They continued to grow and multiply for the next 9 days in culture. In the presence of G-CSF, they developed into granulocytic lineage. Unlike macrophages, cells of granulocytic lineage were not able to adhere to a plastic surface and become suspension cells. They appeared to be fragile and short-lived and began to die in culture on day 6. Using these cells from various culture periods, we studied the role of PKC expression during the differentiation process.
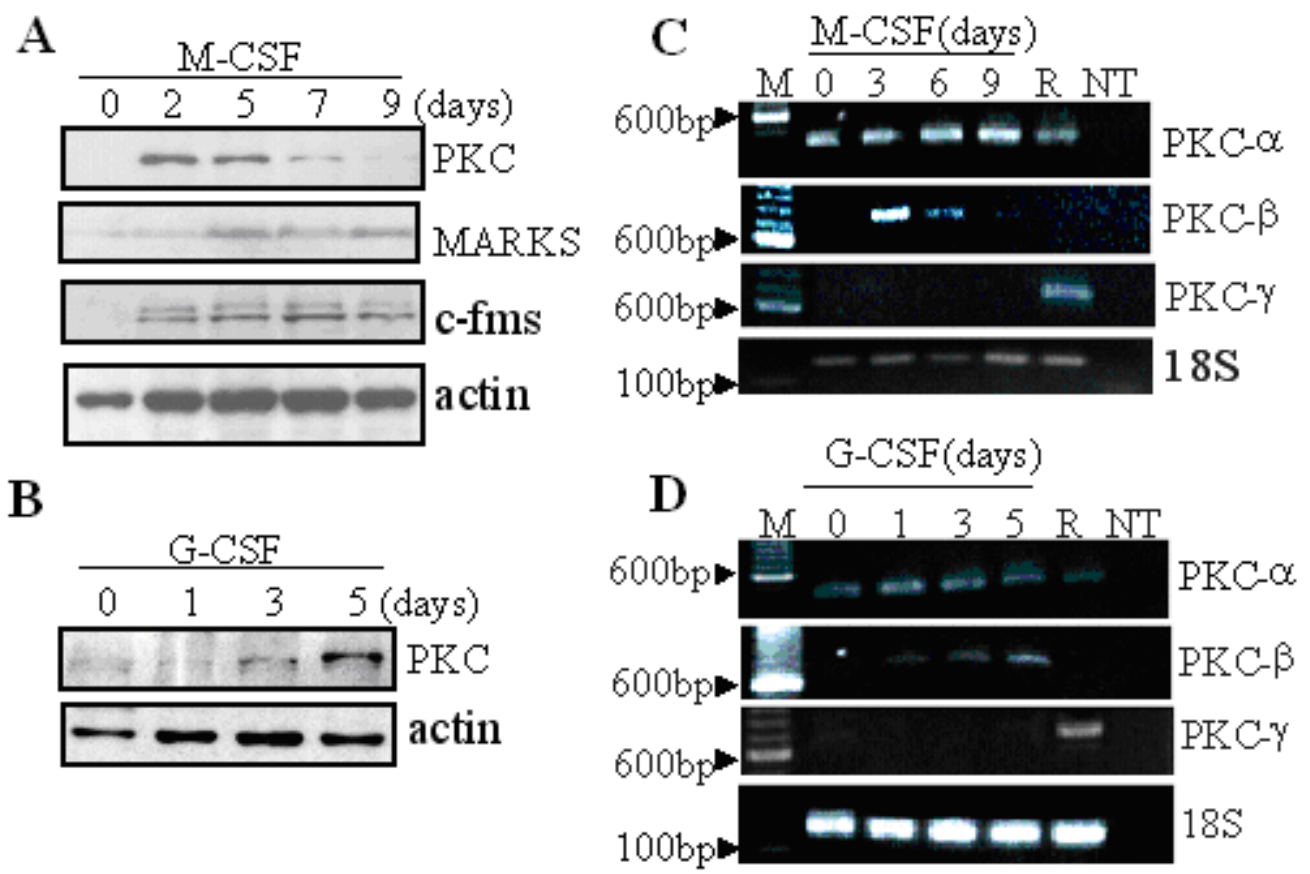

Fig 1. PKC expression on mouse bone marrow-derived macrophage and granulocyte. Bone marrow non-adherent cells $\left(5 \times 10^{5} / \mathrm{ml}\right)$ were cultured in the presence of M-CSF $(10 \mathrm{ng} / \mathrm{ml})$ or G-CSF $(5 \mathrm{ng} / \mathrm{ml})$ for various period of time as indicated. Adherent cells from culture containing M-CSF (A, C) and non-adherent cell culture containing G-CSF (B, D) were harvested, counted, washed. 2 x $10^{5}$ cells were lysed with SDS sample buffer. Samples were subjected to SDS-PAGE and immunoblot analyses with individual antibodies against cPKC (pan), MARKS, c-fms and actin (A, B). In addition, cells were lysed with Trizol Reagent for total RNA isolation. One $\mu \mathrm{g}$ of total RNA was used to generate the cDNA using random primer and M-MLV reverse transcription enzyme followed by PCR amplification of the individual cDNA using specific primers with standard reaction procedure. RT-PCR products were analyzed by running through $1.5 \%$ agarose gel followed by $0.5 \%$ ethidium bromide staining (C, D). R: RAW264.7 mouse monocyte-macrophage cell line. NT: no template. 
As shown in Fig. 1A, macrophage specific marker, c-fms, was markedly induced in cultures undergoing macrophage but not granulocyte development (Fig. 1A). Freshly obtained bone marrow cells expressed nearly undetectable levels of PKC as analyzed by western blot with a pan anti-PKC $\mathrm{mAb}$. PKC expression was detected in cultures containing M-CSF at day 2; thereafter, the level of PKC declined gradually, and was greatly diminished by day 9 (Fig. 1A). MARCKS (myristoylated alanine-rich $\mathrm{C}$ kinase substrate) protein, one of the major substrates of PKC, was induced on day 2 to 5 , and the levels remained essentially the same for the remaining culture periods (Fig. 1A) [27]. Interestingly, PKC expression began much later in cultures containing G-CSF and reached the maximum level only after five days in culture (Fig. 1B).

Since the levels of PKC declined along with the macrophage differentiation (Fig. 1A), we hypothesize that hydrolases and/or proteasome mediated protein degradation may be involved in the process [16, 28, 29]. Indeed, we found that both calpain and the 20S proteasome subunit were induced along with macrophage differentiation (Fig. 2A). To further identify our hypothesis, Alln (a calpain inhibitor) and MG-132 (a proteasome inhibitor) were added to the bone marrow cultures. Compared with the control group, blocking either calpain activity by Alln or the proteasome degradation pathway by MG-132 increased levels of PKC expression slightly, but did not fully restore the PKC level (Fig. 2B, C).

We then employed RT-PCR to study the expression of PKC isoforms during M-CSF and G-CSF-induced cell differentiation. PKC- $\alpha$ mRNA was constitutively expressed in bone marrow cell cultures and was not affected by either M-CSF or G-CSF (Fig. 1C and D). PKC- $\beta$ mRNA was transiently induced by M-CSF during macrophage differentiation. Within $72 \mathrm{hr}$, PKC- $\beta$ mRNA expression reached a maximum, and then declined to an undetectable level by day 9 (Fig. 1C). In contrast, G-CSF induced a gradual and steady increase of PKC- $\beta$ mRNA during granulocytic differentiation in cultures (Fig. 1D). As expected, no PKC- $\gamma$ mRNA was detected during either macrophage or granulocytic differentiation. In addition, we examined the
mRNA expression of the cPKC isoforms in RAW 264.7 cells, a macrophage tumor cell line. Unlike normal bone marrow-derived macrophages, RAW 264.7 cells expressed both PKC- $\alpha$ and PKC- $\gamma$, but not PKC- $\beta$ mRNA (Fig. $1 \mathrm{C}, \mathrm{D})$.
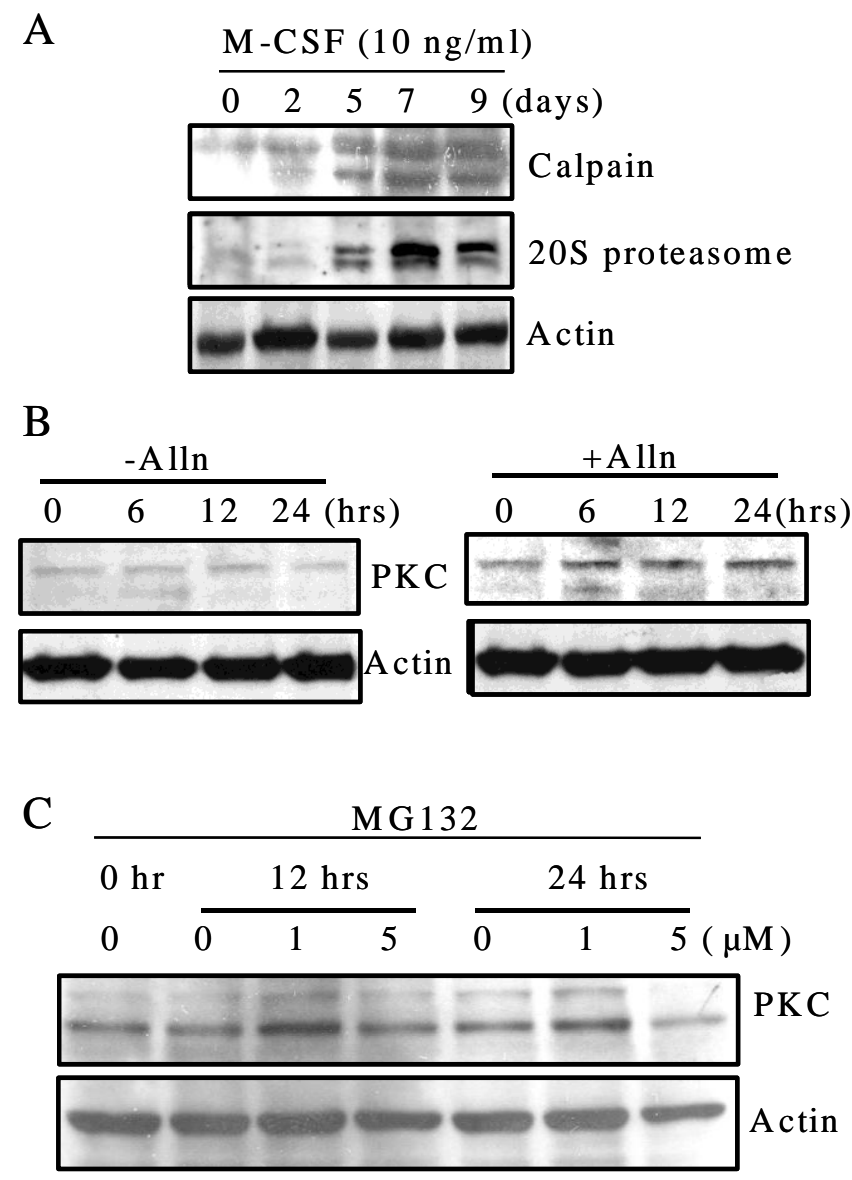

Fig 2. PKC degradation on mouse bone marrow-derived macrophage by calpain and proteasome. Bone marrow non-adherent cells (5 x $10^{5} / \mathrm{ml}$ ) were cultured in the presence of M-CSF (10 $\mathrm{ng} / \mathrm{ml})$ for various periods. Then, adherent cells were harvested, counted, washed and lysed with SDS sample buffer. Samples were loaded and run the SDS-PAGE followed by immunoblot analyses with individual antibodies against calpain, $20 \mathrm{~s}$ proteasome and actin (A). At day 7 of primary Cultures of bone marrow adherent cells, PKC expression level was evaluated by immunoblot assay with anti-PKC (pan) antibody after adding Alln (final concentration $10 \mu \mathrm{M}$ ) (B) or MG-132 (C) to the culture system for different time course. 
NF-kB activation on macrophage differentiation

To further investigate the signaling pathways involved during macrophage and granulocyte differentiation induced by M-CSF and G-CSF, we carried out an EMSA to detect the activation of $\mathrm{NF}-\kappa \mathrm{B}$ in the process. Both mouse and human non-adherent bone marrow cells were cultured with either M-CSF or G-CSF respectively for three days. The adherent macrophage cells and non-adherent granulocytes were starved with serum-free RPMI 1640 containing $0.5 \%$ BSA overnight. Thereafter, the individual groups of cells were re-exposed to M-CSF or G-CSF for the indicated time (Fig. 3). The NF- $\kappa \mathrm{B}$ activity was evaluated by EMSA (Fig. 3A, B). M-CSF induced a transient activation of $N F-\kappa B$ in the nuclear extract from M-CSF treated macrophages. The specificity of the NF- $\kappa \mathrm{B}$ assay was confirmed by blocking completely the sample NF- $\kappa \mathrm{B}$ activity with $\mathrm{NF}-\kappa \mathrm{B}$ specific oligo, but not mutant oligo (Fig. 3C). In contrast, the activation of NF- $\mathrm{BB}$ was not detected in the nuclear extract from granulocytes that had been re-exposed to G-CSF.

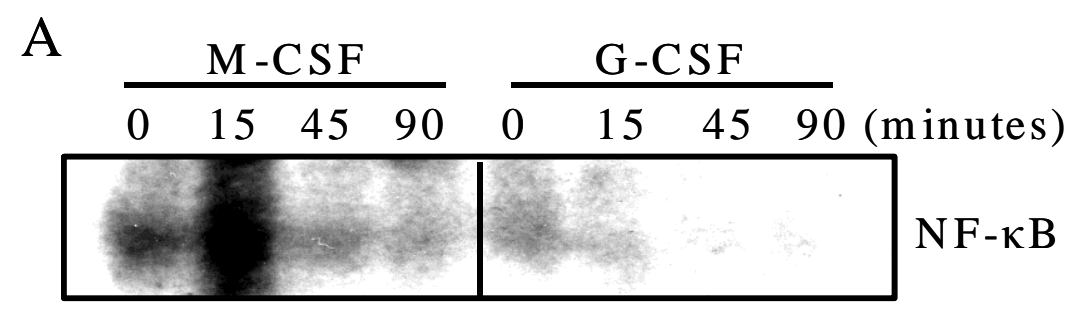

B

\begin{tabular}{|c|c|}
\hline M-CSF & G-CSF \\
\hline $\begin{array}{lllllll}0 & 15 & 30 & 45 & 60 & 90\end{array}$ & $\begin{array}{lll}0 & 1530456090\end{array}$ \\
\hline 00 & \\
\hline
\end{tabular}

C

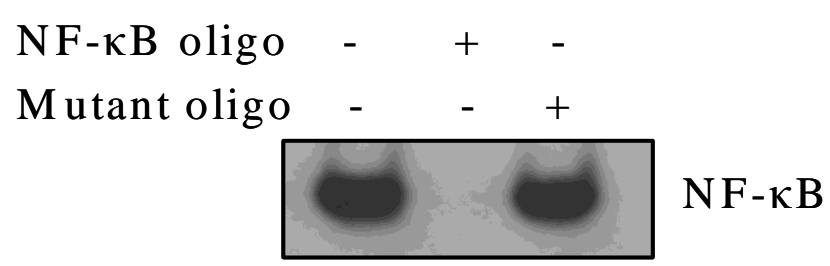

Fig 3. Activation of NF-kB on bone marrow-derived macrophages and granulocytes. Freshly obtained mouse (A) and human (B) bone marrow non-adherent cells $\left(5 \times 10^{5} / \mathrm{ml}\right)$ were cultured in the presence of MCSF $(10 \mathrm{ng} / \mathrm{ml})$ or G-CSF $(5 \mathrm{ng} / \mathrm{ml})$ for three days. After starvation in cytokine-free medium overnight, both adherent macrophage and non-adherent granulocytes were then re-exposed to M-CSF (10 ng/ml) or G-CSF $(5 \mathrm{ng} / \mathrm{ml})$ for indicated time periods. The cells were then lysed and nuclear extracts were isolated, followed by a mobility-shift assay with ATP- $\gamma-{ }^{32} \mathrm{P}$ labeled NF- $\kappa \mathrm{B}$ consensus sequence probe. Total nuclear protein $(5$ $\mu \mathrm{g}$ ) was used per lane. (C) Sample was pre-mixed with either synthetic NF- $\kappa \mathrm{B}$ binding oligo or mutant NF$\kappa \mathrm{B}$ binding oligo prior to EMSA for NF- $\kappa \mathrm{B}$ activity. 


\section{Discussion}

PKCs are a family of serine/threonine protein kinases, which play an important role in cell proliferation, differentiation and maturation. The roles of PKC isoforms during hematopoietic stem cell differentiation/proliferation remain unclear. In this study, we examined the expression of PKC isoforms in primary cultures of mouse bone marrow committed stem cells, CFU-GM, undergoing macrophage and/or granulocytic differentiation induced by M-CSF and G-CSF. We showed that M-CSF and G-CSF induced distinct patterns of PKC- $\beta$ isoform expression in primary culture of bone marrow CFU-GM. Specifically, we found that PKC- $\beta$ mRNA was transiently induced in the early stages of macrophage differentiation, but declined to undetectable levels as macrophages matured. Yet, during granulocytic differentiation, the expression of PKC- $\beta$ mRNA was gradually induced, reaching a maximum and steady level by day 3-5. Since we only tested the PKC- $\beta$ mRNA at day 3 after MCSF stimulation, it is possible that the PKC- $\beta$ mRNA can be induced as early as at day 1 . Therefore, PKC- $\beta$ may play a distinct role during bone marrow cell differentiation in response to stimulus of M-CSF or G-CSF [30-32]. The exact role of $\mathrm{PKC}-\beta$. in regulating macrophage and granulocyte differentiation is not known at present. Studying multi-potential FDCP-Mix A4 cells cultured with IL-3, GM-CSF and G-CSF, Shearman et al. showed that PKC- $\alpha$ might mediate proliferative responses in stem cells; however, PKC- $\beta$ isoforms are involved in cell functions of post-mitotic neutrophils [33]. Conceivably, PKC- $\beta$ may mediate the M-CSF-initiating signal at an early stage of bone marrow cell differentiation toward macrophage lineage, but may be more critical for later stages of G-CSF-induced cell differentiation and function of mature granulocytes.

Unlike PKC- $\beta$, PKC- $\alpha$ mRNA was constitutively expressed in both culture systems. No apparent change of PKC- $\alpha$ mRNA was observed during entire culture periods with either M-CSF or G-CSF. Yet, results from western blot analysis with pan anti-PKC antibody were not completely consistent with those of mRNA, suggesting that $\mathrm{PKC}-\alpha$ protein translation may not take place in bone marrow cultures, or that the amount of PKC- $\alpha$ protein may exist in low levels that were not detected by the pan anti-PKC antibody used in this study. Thus, the total amount of PKC proteins detected in western blot (Fig. 1) was primarily from PKC- $\beta$ rather than from PKC$\alpha$. In a previous study, Pierce et al reported that M-CSF promoted PKC- $\alpha$ translocation from the cytosol to the nucleus, which was an important signal associated with macrophage development in primary mammalian hematopoietic progenitor cells [20].

PKC- $\gamma$ was not expressed in cultured bone marrow during either macrophage or granulocyte development. Nor is PKC- $\gamma$ expressed in freshly obtained bone marrow cells. This finding suggests that PKC- $\gamma$ expression may not be involved during macrophage and granulocyte differentiation. This is not unexpected, since PKC- $\gamma$ is believed to be important to the neural plasticity within the spinal cord after nerve injury [22]. Still, PKC- $\gamma$ may play a role in malignant transformation, since we did detect PKC- $\gamma$ expression in RAW264.7 cells, a mouse monocyte/macrophage tumor cell line with uncontrolled proliferation in vitro. Further experiments are warranted to examine whether $\mathrm{PKC}-\gamma$ plays a role in tumorigenesis.

In addition to the expression of $\mathrm{PKC}$ isoforms, we examined the role of $N F-\kappa B$ activation during macrophage/granulocyte differentiation induced by M-CSF and G-CSF. $\mathrm{NF}-\kappa \mathrm{B}$ activation was detected only in M-CSF induced macrophage differentiation but not in GCSF induced granulocyte differentiation. This finding strongly indicates that $\mathrm{NF}-\kappa \mathrm{B}$ activation is a crucial signaling event necessary for steering CFU-GM toward macrophage differentiation and development. Taken together, our results showed that differentiation of hematopoietic stem cells into mature cells of distinct lineages are regulated by multiple signaling pathways, which include PKC isoforms, NF- $\kappa \mathrm{B}$, and other events. Our current studies using gene array approaches may yield more details about the complex mechanisms involved in the process. 


\section{Acknowledgements}

This work was supported by Public Health Service Grant CA 73212 awarded by the National Cancer Institute, Department of Health and Human Services, U.S.A

\section{References}

1. Tamura, T., et al., FMIP, a novel Fms-interacting protein, affects granulocyte/macrophage differentiation. Oncogene, 1999. 18(47): p. 648895.

2. Sherr, C.J., et al., The c-fms proto-oncogene product is related to the receptor for the mononuclear phagocyte growth factor, CSF-1. Cell, 1985. 41(3): p. 665-76.

3. Hamilton, J.A., CSF-1 signal transduction. J Leukoc Biol, 1997. 62(2): p. 145-55.

4. Lin, H., C. Chen, and B.D. Chen, Resistance of bone marrow-derived macrophages to apoptosis is associated with the expression of $X$-linked inhibitor of apoptosis protein in primary cultures of bone marrow cells. Biochem J, 2001. 353(Pt 2): p. 299-306.

5. Lin, H., et al., Activation of the MEK/MAPK pathway is involved in bryostatinl-induced monocytic differenciation and up-regulation of $X$-linked inhibitor of apoptosis protein. Exp Cell Res, 2002. 272(2): p. 192-8.

6. Nicholson, S.E., et al., Distinct regions of the granulocyte colony-stimulating factor receptor are required for tyrosine phosphorylation of the signaling molecules JAK2, Stat3, and p42, p44MAPK. Blood, 1995. 86(10): p. 3698-704.

7. Katayama, N., et al., Putative involvement of protein kinase $C$ in proliferation of human myeloid progenitor cells. Blood, 1989. 73(1): p. 123-30.

8. Yoon, Y.M., et al., Maintenance of differentiated phenotype of articular chondrocytes by protein kinase $C$ and extracellular signal-regulated protein kinase. $\mathrm{J}$ Biol Chem, 2002. 277(10): p. 8412-20.

9. Kolata, G., Clues to cell growth and differentiation. Science, 1983. 220(4594): p. 291-2.

10. Park, H.Y. and B.A. Gilchrest, Protein kinase $C$ : biochemical characteristics and role in melanocyte biology. J Dermatol Sci, 1993. 6(3): p. 185-93.

11. Nishikawa, M. and S. Shirakawa, The expression and possible roles of protein kinase $C$ in haematopoietic cells. Leuk Lymphoma, 1992. 8(3): p. 201-11.

12. Parker, P.J. and A. Ullrich, Protein kinase C. J Cell Physiol Suppl, 1987. Suppl 5: p. 53-6.

13. Koren, R., et al., Protein kinase $C(P K C)$ isoenzymes immunohistochemistry in lymph node revealing solution-fixed, paraffinembedded bladder tumors. Appl Immunohistochem Mol Morphol, 2000. 8(2): p. 166-71.

14. Goldberg, M. and S.F. Steinberg, Tissuespecific developmental regulation of protein kinase C isoforms. Biochem Pharmacol, 1996. 51(8): p. 1089-93.

15. Wada, H., et al., Cell type-specific expression of the genes for the protein kinase $C$ family: down regulation of $m R N A$ s for $P K C$ alpha and $n P K C$ epsilon upon in vitro differentiation of a mouse neuroblastoma cell line neuro $2 a$. Biochem Biophys Res Commun, 1989. 165(1): p. 533-8.

16. Ohno, S., et al., Structural and functional diversities of a family of signal transducing protein kinases, protein kinase $C$ family; two distinct classes of PKC, conventional cPKC and novel $n P K C$. Adv Enzyme Regul, 1991. 31: p. 287-303.

17. Nishikawa, K., et al., Characterization of endogenous substrates for novel-type protein kinase $C$ as well as conventional-type protein kinase $C$ in primary cultured mouse epidermal cells. Cell Signal, 1992. 4(6): p. 757-76.

18. Kikkawa, U., et al., Protein phosphorylation and mechanism of action of tumor-promoting phorbol esters. Adv Cyclic Nucleotide Protein Phosphorylation Res, 1984. 17: p. 437-42.

19. O'Brian, C.A., Protein kinase C-alpha: a novel target for the therapy of androgenindependent prostate cancer? (Reviewhypothesis). Oncol Rep, 1998. 5(2): p. 305-9.

20. Pierce, A., et al., An activated protein kinase $C$ alpha gives a differentiation signal for hematopoietic progenitor cells and mimicks macrophage colony-stimulating factor- 
stimulated signaling events. J Cell Biol, 1998. 140(6): p. 1511-8.

21. Huang, F.L., et al., Differential downregulation of protein kinase $C$ isozymes. $\mathrm{J}$ Biol Chem, 1989. 264(7): p. 4238-43.

22. Mao, J., et al., Pain-related increases in spinal cord membrane-bound protein kinase $C$ following peripheral nerve injury. Brain Res, 1992. 588(1): p. 144-9.

23. Yamasaki, H., et al., Membrane interaction and modulation of gene expression by tumor promoters. Princess Takamatsu Symp, 1983. 14: p. 221-33.

24. Sinclair, N.R., Immunoreceptor tyrosine-based inhibitory motifs on activating molecules. Crit Rev Immunol, 2000. 20(2): p. 89-102.

25. Oshevski, S., et al., Differential expression of protein kinase $C$ isoform transcripts in human hematopoietic progenitors undergoing differentiation. Biochem Biophys Res Commun, 1999. 263(3): p. 603-9.

26. Tseng, C.P. and A.K. Verma, Functional expression and characterization of the mouse epitope tag-protein kinase $C$ isoforms, alpha, beta I, beta II, gamma, delta and epsilon. Gene, 1996. 169(2): p. 287-8.

27. Arbuzova, A., A.A. Schmitz, and G. Vergeres, Cross-talk unfolded: MARCKS proteins. Biochem J, 2002. 362(Pt 1): p. 1-12.

28. Tanabe, F., S.H. Cui, and M. Ito, Abnormal down-regulation of $P K C$ is responsible for giant granule formation in fibroblasts from
CHS (beige) mice--a thiol proteinase inhibitor, E-64-d, prevents giant granule formation in beige fibroblasts. J Leukoc Biol, 2000. 67(5): p. 749-55.

29. Gebrosky, N., et al., m-Calpain activation/depletion is associated with androgen-induced reduction of protein kinase $C$ and proliferation of male accessory sex organ smooth muscle cells. J Urol, 1997. 157(2): p. 662-8.

30. Xie, B., A. Laouar, and E. Huberman, Fibronectin-mediated cell adhesion is required for induction of 92-kDa type IV collagenase/gelatinase (MMP-9) gene expression during macrophage differentiation. The signaling role of protein kinase C-beta. $\mathrm{J}$ Biol Chem, 1998. 273(19): p. 11576-82.

31. Gamard, C.J., et al., Specific role for protein kinase $C$ beta in cell differentiation. Cell Growth Differ, 1994. 5(4): p. 405-9.

32. Dieter, P. and H. Schwende, Protein kinase $C$ alpha and -beta play antagonistic roles in the differentiation process of THP-1 cells. Cell Signal, 2000. 12(5): p. 297-302.

33. Shearman, M.S., et al., Haemopoietic stem cell development to neutrophils is associated with subcellular redistribution and differential expression of protein kinase $C$ subspecies. $\mathrm{J}$ Cell Sci, 1993. 104 ( Pt 1): p. 173-80. 